\title{
On-line Education to Develop Complex Reasoning Skills in Organic Chemistry
}

\author{
Patricia Shapley \\ University of Illinois at Urbana-Champaign
}

\begin{abstract}
Chemistry 331 is an upper level organic chemistry course for students interested in health related careers with an enrollment of approximately 150 students per semester. It assumes that students have a basic knowledge of organic chemistry principles and concepts and it builds on this base with advanced concepts in organic synthesis, mechanism of reactions, and spectroscopy with a biological perspective. Three years ago we moved to an on-line format to better serve the needs of students with disparate backgrounds and to help them master the concepts and applications of organic chemistry at an advanced level. The course includes on-line lectures with embedded problems, computer-graded quizzes, and online discussion sections. The exams are in the standard format and are proctored on campus or in off campus testing centers. The format of the course increases flexibility for the students, increases interaction among students and between students and faculty, and improves student performance on examinations that require complex reasoning skills.
\end{abstract}

\section{INTRODUCTION}

Chemistry 331 is an upper level organic chemistry course for students interested in health-related careers. Many students complete this course to prepare for MCAT and chemistry or biochemistry GRE examinations. At the University of Illinois these students will typically take a one-semester overview of organic chemistry lecture course and an organic laboratory course in the sophomore year (Chemistry 231 and Chemistry 234). Typical enrollment for Chemistry 231 is 500 to 700 students per semester. A smaller number of Chemistry majors take a two-semester sequence of organic chemistry lecture courses at that time (Chemistry 236 and Chemistry 336).

We have always offered a second semester of organic chemistry in the spring semester for students who have completed Chemistry 231 or some other chemistry course. Chemistry 331 is not the second half of a year-long sequence. It assumes students have a basic knowledge of organic chemistry principles and concepts and it builds on this base with advanced concepts in organic synthesis, mechanism of reactions, and spectroscopy with a biological perspective. As more medical schools and pharmacy departments require a second semester of organic chemistry from their applicants, the enrollment of Chemistry 331 has increased from approximately 100 to more than 300 students per year. Most students in the course are in their junior or senior year. Some graduate students from departments in the Life Sciences also enroll each year.

A major problem with teaching this course effectively is the wide variation in student background and preparation coupled with the large class size. A minority are University of Illinois Chemistry majors with very strong backgrounds in chemistry. Others are transfer students from community colleges. Their previous courses in chemistry vary greatly in content. The majority of the students are University of Illinois undergraduates with majors in liberal arts and sciences such as Biology, Psychology, History, etc. Many of the students have a two to three semester gap between their first course in organic chemistry and this one. 
This course was initially offered in the standard lecture format. Three, 50-minute lectures per week were presented to students in a large lecture hall using a chalkboard and overhead projection slides. The number of students attending lecture was significantly lower than the number registered and very few students asked questions during or after the lectures. Few students came to office hours, except for those office hours immediately before examinations. Highly motivated students with good backgrounds in chemistry performed very well in the course but the average student was confused by some concepts and did not develop a sophisticated understanding of the field. Many poorly prepared students dropped out of the course or failed it.

The course developed in a stepwise fashion from the standard lecture format to a full Web course. More computergenerated content was added to lectures and a computer projection system was used in lectures. Because students wanted to review these materials outside lecture, they were posted on the Web and linked to a course homepage. As more lecture material was posted, fewer students actually attended the live lectures. Those coming to lectures wanted to go over examples and problems related to the topics rather than simply hearing a lecture. Finally, three years ago we added a fall semester section of the course in an on-line format. This was evaluated and approved by the Department of Chemistry and the College of Liberal Arts and Sciences as Chemistry 331W. All lecture material was moved to the Web and on-line quizzes, interactive example problems, surveys, and conferencing were added. Students can attend an optional review/problem session once a week and can see visit the professor during expanded office hours but there are no live lectures for the course in the fall. In the spring semester, Chemistry 331 is still taught in the traditional lecture format.

\section{RATIONALE}

The format of the course was changed to better serve the needs of students with disparate backgrounds and to help them master the concepts and applications of organic chemistry at an advanced level.

On-line education in an upper level organic chemistry course can be more effective than the traditional lecture mode in developing complex reasoning skills. The traditional lecture format is essentially passive and promotes memorization of facts. This can work well in the first semester course in organic chemistry where students acquire a background of facts. It works poorly in an advanced course where students require complex reasoning skills for reaction mechanisms, molecular spectroscopy, and in the total synthesis of organic molecules.

The students in the advanced course must apply the facts to problems requiring complex reasoning. To master and apply concepts in reaction mechanism, students must know the basic kinds of reactions that organic molecules undergo. They must understand why these reactions take place by analyzing the reactant molecules to determine sites of high and low electron density, deciding whether these sites will be basic/nucleophilic or acidic/electrophilic. Then they must be able to extend this analysis to molecules and reactants they have not encountered before.

To apply organic spectroscopy to research problems students must understand the basic concepts behind the spectroscopic technique. They must know the facts on chemical shift (NMR spectroscopy), frequency of stretching vibrations (IR spectroscopy), etc. They must analyze the symmetry of an organic molecule. This requires the ability to see the molecule in three dimensions, and visualize rotations and molecular motions. They must be able to use the information they have to go from a spectrum to a molecule or from a molecule to the spectrum.

Organic synthesis is probably the most demanding aspect of an advanced organic chemistry course. Students must know a great deal of information about the reactions typical of each functional group. They must understand mechanisms of reaction well enough to be able to visualize the inverse of these reactions because syntheses typically start by working backwards. The synthesis of a complex organic molecule really requires the "synthesis" of all the student's knowledge of organic reactivity and requires a high level of complex reasoning, imagination and fundamental knowledge of the facts. 
An additional advantage of the on-line course is that we expand the pool of students we serve. People who are employed full-time and mothers with young children can take the course over the Internet. Students with weak backgrounds can take the course on a flexible schedule option that gives them time and additional resources to cover the basics before they move on to advanced topics.

Cost of delivery was not a reason for change. It requires approximately the same amount of departmental resources to teach this course in the on-line mode as other lecture courses. We use some of the resources differently. For example, teaching assistants (TAs) in Chemistry $331 \mathrm{~W}$ spend most of their time working with small groups of students in the on-line conferences. Previously, they were exclusively graders for quizzes and exams.

Students evaluate all chemistry lecture courses at the end of each semester. Along with this final evaluation, Chemistry 331 has frequent anonymous surveys to gather data on how students use the course materials, their level of satisfaction with the course, and to collect their opinions on a variety of topics related to the course and the information presented. Additionally, the teaching staff (TAs and the instructor) receive comments from students with the on-line conference.

\section{BACKGROUND INFORMATION}

At the time Chemistry 331 was converted to an on-line course, there were a number of ALN resources at the University of Illinois. The Sloan Center for Asynchronous Learning Environments (SCALE) was providing information and other resources for faculty on this campus. UI-On-line was beginning to promote distance education from the University of Illinois. Professor Alfred Hubler and his staff were developing the software package CyberProf and using this in a number of courses on campus.

Professor Stanley Smith in Chemistry was a pioneer in the use of computers for science education. He created selfpaced organic chemistry lessons on the Plato system, along with videodisks and other information for general chemistry. His efforts and those of the general chemistry staff to increase the availability of computers in the firstyear chemistry courses were enormously important. Drs. Iris Stoval, Loretta Jones, Barbara Whitmarsh, and Roxy Wilson investigated course software packages and developed on-line content for general chemistry courses. There were no other upper level courses using extensive on-line materials at the time. Currently, 17 chemistry courses use the WebCT course package, two use Cyberprof, and many others have course Web pages but Chemistry 331 is the only course offered in a completely on-line mode.

In $1998,70 \%$ of students who began Chemistry $331 \mathrm{~W}$ in the fall semester successfully completed the course with a passing grade. This may seem low but it is consistent with the success rate of the lecture version of this course and with other, high-enrollment chemistry courses. Some of these students drop the on-line course and take the standard lecture course the following semester because they prefer live lectures to Web-based instruction. We know this from initial surveys of the spring lecture course. Of course, the fall semester Web course also includes students who have dropped the previous spring semester lecture course because they disliked the format. Other students drop the course sometime after the first exam because they believe their grade is unacceptable. The average grade in a chemistry course at this level is a B-. Many of the students who drop the course are actually performing well but not well enough to achieve the grade of A they want for medical school admission. Four students enrolled through Extramural Programs as distance students. All of them completed the course.

Other students drop Chemistry 331 because their backgrounds are too weak to succeed in the course or because it has too high a workload. After the first examination, these students were offered the option of moving to a flexible schedule section of the course in which they would have additional time to complete course material but would be required to see the professor or a TA once a week to go over their progress. Twenty-five students $(18 \%$ of the original class) participated in the flexible schedule option for at least part of the semester. This group included all of the distance students, many of the minority students, and some of the transfer students. Only one member of the group dropped the course. All the others successfully completed it. 


\section{METHODS}

We have used two different course packages with their built-in conferencing software and have also used a separate conferencing software program. Initially, Chemistry $331 \mathrm{~W}$ used CyberProf for the delivery of course material, quizzes, and conferencing. Professor Hubler and his team in the Physics Department set up the course package and ran it on their server. We then moved to the WebCT course package on Chemistry Department servers. This gave students faster access to course materials. WebCT also has built-in communication software but it is slow and difficult to use with graphics. SCALE gave us access to WebBoard conferencing and maintains this program on their servers. We have found that WebBoard is superior to the communication systems in either CyberProf or WebCT for our needs.

Students use only two software programs - ChemWeb and Netscape. Both programs are free to the students and work on both PCs and Macintosh computers. ChemWeb is a chemistry drawing program from SoftShell that allows students to easily draw chemical structures and reactions and save these in GIF format for posting on the Web. Netscape is the Web browser we recommend. Students can access all aspects of the course from the Web using Netscape.

SCALE provided us with a grant that allowed the purchase of a computer for the TAs and funds for some TA support in the initial stages of the course. They continue to provide the WebBoard conferencing software and technical support for that. Professor Smith provides the WebCT courseware package with the funds from his Murchison-Mallory Endowed Chair in Chemistry. Currently, we have a level of TA support for the course from the Department of Chemistry that is higher than the standard format for Chemistry 331 but similar to other chemistry courses in the department.

How does the student's experience differ in the traditional lecture version of Chemistry 331 and the new, Web version? The table below shows the instructional resources typically used in Chemistry 331 . This is a large lecture course without scheduled TA quiz sessions. The Web version of Chemistry 331 allows us to provide the students with more resources rather than fewer.

\begin{tabular}{|l|l|}
\hline \multicolumn{1}{|c|}{ Chemistry 331 } & \multicolumn{1}{|c|}{ Chemistry 331W } \\
\hline 50-minute live lecture (instructor), 3 per week & $\begin{array}{l}\text { Self-paced lecture material over the Internet, 3 per week } \\
\text { 1 hour live review session (instructor, 100 Noyes Lab), } \\
\text { per week. 1 hour interactive discussion of lecture materials } \\
\text { (instructor and students) in the WebBoard discussion } \\
\text { forum, 2 per week }\end{array}$ \\
\hline $\begin{array}{l}\text { Textbook: } \\
\text { reading assignments, problem set assignments }\end{array}$ & $\begin{array}{l}\text { CD-ROM for review of lecture material, practice problems } \\
\text { Textbook for reference with suggested reading based on } \\
\text { the on-line lectures }\end{array}$ \\
\hline Instructor office hours, 1-2 per week & Instructor office hours, 3 per week \\
\hline $\begin{array}{l}\text { Organic TA Help Desk, 212 Chemistry Annex } \\
\text { TA office hours, 2-3 per week }\end{array}$ & $\begin{array}{l}\text { Organic TA Help Desk, 212 Chemistry Annex } \\
\text { TA office hours, 3 per week } \\
\text { TA help on the WebBoard Conference: 24 hours per week }\end{array}$ \\
\hline Occasional class quizzes & $\begin{array}{l}\text { Computer quizzes: multiple choice, matching, short } \\
\text { answer, or essay format, 3 per week } \\
\text { Self-test questions, at least 6 per lecture } \\
\text { Example problems and practice problems, 9-12 per lecture }\end{array}$ \\
\hline $\begin{array}{l}\text { Hour examinations, 3-4 per semester, long answer, } \\
\text { proctored }\end{array}$ & \begin{tabular}{l} 
Hour examinations, 4 per semester, long answer, proctored \\
\hline
\end{tabular} \\
\hline
\end{tabular}


During the semester, a student completes 40 lectures on topics ranging from chemical bonding to the organic chemistry of DNA. Each lecture consists of text, pictures, animations, and many imbedded problems on the Web or on a $\mathrm{CD}$. The emphasis in the material is problem solving rather than memorization. The lecture includes a summary of the topic and self-test problems. A student reads through the summary and additional information on each of several sub-topics then answers the self-test problems. The self-test problems are not graded but provide immediate feedback to help the student judge the extent of his or her understanding of the material. The embedded problems are linked to answers and to detailed explanations. Pictures and text are hyperlinked to provide additional information when the student needs it. There are also numerous links to information on other Web sites. A standard Organic textbook serves as a reference and reading lists are suggested for textbooks that correspond with our lecture topics.

Next, the student takes a computer-graded, five-point quiz on the lecture material. Quizzes usually consist of five questions. There are ten versions of each question prepared and these versions are randomly scrambled so that the quizzes vary from student to student. Quizzes are open-book but include a time limit. A student may take two versions of the quiz for each lecture. The better of the two grades is recorded.

Completing the lecture material, including working through some practice problems, the self-test problems, and a quiz take an average of two hours. A student's work is self-paced but there is a deadline for each quiz. Because of the nature of the on-line course, students are permitted to begin the fall semester course work in Chemistry $331 \mathrm{~W}$ over the summer. This gives many students a head start on the work and increases their flexibility in the fall.

A key aspect of the on-line course is the high degree of interaction between teaching staff and students. We use both synchronous (Chat) and asynchronous modes of communication within WebBoard. This program allows students and staff to post pictures of chemical structures, reactions, and mechanistic schemes in the conference. Students participate in at least one WebBoard conference each week but may use the conference at any other time as well. In a typical conference, approximately ten students and a TA work through some problems related to lecture topics and discuss any difficulties the students are having with the material. We have scheduled conferences for days, evenings, and weekends to fit student schedules. We also have office hours and a weekly, optional review session. Students use WebBoard much more heavily than live office hours.

There is an hour examination after lecture 8,20,30, and 40. Each exam is comprehensive and consists of longanswer (not multiple choice) problems on paper. We have multiple versions of each exam and administer these each Wednesday throughout the semester. Distance students take their exams at testing centers convenient to them. We mail the exams directly to a proctor who administers the exam. Students may go over the graded exam with me or with a TA but we do not return exams to the students for security reasons. The instructor assigns a final grade to each student based on his or her percentage of total points after the fourth examination.

\section{RESULTS}

We conducted on-line, anonymous surveys throughout each semester of Chemistry 331W. In 1997 and in 1998, we had four surveys each semester including one conducted by SCALE.

The initial surveys provided information on the students' backgrounds, including computer experience and the availability of computers to the students. We found most students were juniors or seniors with an average of two to three semesters since the previous chemistry course. The level of students' experience with computers and the number of students with personal computers increased significantly from 1997 to 1998 . The average student rated his or her understanding of organic chemistry to be only fair at the start of the course and students were more confident of their understanding of bonding and stereochemistry than of synthesis and reactivity of organic molecules. In 1997, most students said they enrolled in Chemistry $331 \mathrm{~W}$ because it better fit their schedules than the lecture course in the spring semester. By 1998, the majority of students enrolled because they liked the added flexibility of a Web course. 
In later surveys, students were asked their opinions on all aspects of the course, including lecture notes, quizzes, conferences, exams, review sessions, office hours, and the overall level of difficulty. We modified the nature of the quizzes, emphasis of the lecture material, and aspects of the WebBoard conference based on student comments. Student input allowed us to improve course delivery throughout each semester. We also added the TA office hours based on requests through our surveys. This was less successful. Students like the idea of live office hours but almost never use them!

The final survey included questions identical to the ICES evaluation forms used by other undergraduate classes. The level of student satisfaction was high. Students compared Chemistry $331 \mathrm{~W}$ favorably to other chemistry classes they had taken. The majority $(<70 \%)$ of students said that they would like to take other courses on-line. In their comments, many students said the flexibility of the course was the most important aspect. The most common complaint was they worked harder than they expected and had to teach themselves the material.

Student performance as measured by examinations was as good or better in Chemistry $331 \mathrm{~W}$ than in lecture sections of the course taught by Professor Shapley. The faculty member who taught the spring semester section of the class for the past two years would not allow a direct comparison between the fall semester on-line course and the standard lecture course for the 1997-8 and 1998-9 academic years. Shapley was able to compare examination results from spring 1995 and spring 1996 with the on-line courses in fall 1997 and fall 1998. The average score for each of the first two exams in all four semesters was $55 \%$ plus or minus $2 \%$. In all cases the high score on an exam set was $>95$ points and the low score was $<20$ points. Exam questions were similar and topics covered were identical.

In the second half of the on-line course, Shapley increased the level of difficulty in the examinations by replacing some short-answer problems with more complex ones on the total synthesis of organic and bio-organic molecules. All exams (two semesters of Chemistry 331 and two semesters of Chemistry $331 \mathrm{~W}$ ) included similar problems on reactions of organic molecules, mechanisms of reaction, spectroscopy, and simple synthesis problems. The on-line students scored slightly better $(2 \%)$ on these exams than the lecture students even though their exams included some questions of greater difficulty.

In the fourth examination, a set of questions was included from a standardized graduate level placement examination in organic chemistry from the American Chemical Society. We use this exam to test graduate students when they begin their Ph.D. programs at the University. Chemistry $331 \mathrm{~W}$ students answered these questions correctly $60 \%$ of the time. This is identical to the average score for the graduate students in this field and indicates a very good level of understanding.

The conventional wisdom is that traditional lectures with a faculty member working through syntheses on a chalk board and explaining his reasoning to students is the most effective method to teach organic synthesis. Synthesis problems are complex and require students to use their understanding of the reactivity of functional groups along with some imagination. Practice helps but memorization of facts or other problems is ineffective. Why did on-line students who did not attend this type of lecture outperform the conventional lecture students on synthesis problems?

Students in Chemistry $331 \mathrm{~W}$ complained they had to teach themselves the material and it is certainly true. We gave students the information and resources they needed but they had to master the concepts by working through series of problems and using the resources as necessary. This active learning in organic chemistry gave students a better understanding of the field and the ability to apply what they learned to organic and bio-organic synthesis.

We had particular success with the flexible schedule section of the course. Students with weak backgrounds in science and math need extra time in the beginning to master the basic concepts. A typical lecture course proceeds for all students at the same rate. This may be too slow for well-prepared and highly motivated students and is certainly too fast for students with special needs. An on-line course can allow students to progress at their own rates. We found the flexible schedule coupled with weekly face-to-face contact between these students and the teaching staff 
helped transfer students and other students with weak backgrounds in chemistry to successfully complete Chemistry $331 \mathrm{~W}$. This option may be useful in helping to increase the success of underrepresented minorities in math and science courses at the University.

\section{ABOUT THE AUTHOR}

Patricia A. Shapley is Professor of Chemistry, University of Illinois in Urbana. She received her B.A. from Boston University in 1977 and her Ph.D. from M.I.T. in 1981 and was a postdoctoral fellow at the Institut Louis Pasteur de Strasbourg, France, 1981-2. She received a Sloan Foundation Fellowship in 1991. Research in the Shapley group involves the synthesis of new, organometallic complexes with oxo, nitrido, imido and sulfido ligands and the use of these in the selective oxidation of organic molecules.

Contact: University of Illinois, 601 South Goodwin Avenue, Urbana, Illinois 61801; Telephone: 217-244-4186; Fax: 217-333-2685; E-mail: pshapley@uiuc.edu. 



\section{On-line Education to Develop Complex Reasoning Skills in Organic Chemistry}

Pat Shapley

\section{Discussant: Saundra Theis, University of Illinois at Chicago}

Thank you for a wonderful example of a class that stimulates the development of complex reasoning skills, or critical thinking. I believe that the best response to this example is to spend some time talking about active learning, as it is active learning that enhances critical thinking.

Active learning includes

- Social and cognitive engagement with course material

- More than memorization and regurgitation of facts

- Exposure to essential material that consists of more than putting lecture notes on-line. Sometimes what is effective is to provide information, then have the student apply it with a short quiz or case study.

- Enhanced critical thinking

In a Delphi study by Facione (1990) an ideal critical thinker "is habitually inquisitive, well-informed, trustful of reason, open-minded, flexible, fair-minded in evaluation, honest in facing personal biases, prudent in making judgements, willing to reconsider, clear about issues, orderly in complex matters, diligent in seeking relevant information, reasonable in the selection of criteria, focused in inquiry, and persistent in seeking results which are as precise as the subject and the circumstances permit."

The cognitive skills of critical thinking are

- Analysis

- Evaluation

- Inference

- Interpretation

- Explanation

- Self-regulation

Active learning is self-paced. There is an opportunity to apply learning through quizzes or discussion. Discussion in an on-line format can be synchronous or asynchronous. Both types of discussion can have similar benefits. There is interaction in both. They require knowledge and application of knowledge for the student to be able to interact. Discussion requires the student to put ideas into a coherent form. Responses from others may request clarification, expansion, or express disagreement. This interaction requires that the original student defend or refine the comment. Discussion activates intellectual processing. The process leads to collaborative learning that also aids complex reasoning skills. Better discussion can increase the level of interactive thinking. A written response takes on more importance than just saying it and requires more intellectual effort that aids comprehension and retention. A discussion that is recorded in an on-line format provides students access to the combined knowledge of the group, not just the knowledge of the instructor. While both synchronous and asynchronous discussions can be 
effective — some faculty and students prefer asynchronous discussions. Participants are not time-bound and they have more time to think about their responses.

The reaction of students to active learning is mixed. Some think they are teaching themselves the material. Faculty need to let students know from the beginning of the course why they are using active learning methods and the benefit they see in these methods. Students say it takes more of their time. Other students express dissatisfaction that they are not being taught by an expert. To remedy this criticism faculty need to develop better ways of connecting with students who are at a distance so they know an expert is still teaching the course.

The example of on-line teaching provided for us by Dr. Pat Shapley uses techniques of active learning to enhance the experience of students.

\section{REFERENCES}

Facione, P. A. Critical thinking: A statement of expert consensus for purposes of educational assessment and instruction. The Delphi Report: Research findings and recommendations prepared for the committee on pre-college philosophy, Neward, DI: American Philosophical Association, Eric Document Reproduction Service No. ED 315423, 1990.

\section{ABOUT THE DISCUSSANT}

Saundra Theis is Associate Professor of Medical Surgical Nursing and Associate Dean for Academic Programs at the University of Illinois at Chicago College of Nursing. She has been involved in nursing education for over 30 years, including experience with multimedia and active learning. She is chair of the Council for Excellence in Teaching and Learning at UIC and has won several teaching awards. She was a member of the University of Illinois Teaching at an Internet Distance Seminar.

Contact: College of Nursing, University of Illinois at Chicago, 845 S. Damen Avenue, M/C 802, Chicago, Illinois 60612; Telephone 312-996-5706; Fax 312-996-8066; E-mail: stheis@uic.edu. 